\title{
Perceptual and lexical components of auditory repetition priming in young and older adults
}

\author{
MAURA PILOTTI and TIM BEYER \\ Washington University, St. Louis, Missouri
}

\begin{abstract}
In the present study, we examined whether age modulates the processing of lexical and perceptual information in auditory implicit and explicit memory tests. Young and older adults performed a surface encoding task on spoken and printed words and then either identified degraded words or made explicit recognition judgments. The implicit test of perceptual identification yielded no evidence of age-related declines in the processing of either lexical information or coarse perceptual details (modality of presentation). The same test, however, produced marked age-related declines in the processing of fine-grained perceptual details (voice) when subjects were not familiarized with the talkers' voices prior to the encoding task. Marked age differences were also observed in recognition memory. These findings suggest that although aging preserves the encoding and incidental retrieval of lexical and coarse perceptual information, it affects the encoding of fine-grained perceptual information and deliberate retrieval processes.
\end{abstract}

Contemporary accounts of memory research distinguish between implicit and explicit memory tests. In explicit tests, such as recognition and recall, subjects consciously attempt to recollect information encountered in an earlier phase of the experiment. In implicit tests, subjects perform tasks that are ostensibly unrelated to the previously presented information, such as identifying degraded words or completing word stems or fragments with the first word that comes to mind. In these tests, the easier processing of a stimulus caused by prior presentation of that stimulus is known as repetition priming.

A common finding of investigations of repetition priming that have involved healthy young adults (see Roediger \& McDermott, 1993) is that format changes between study (encoding) and test, such as those pertaining to modality of presentation(Jackson \& Morton, 1984; Pilotti, Bergman, Gallo, Sommers, \& Roediger, 2000; Rajaram \& Roediger, 1993), speaker's voice (Church \& Schacter, 1994; Pilotti et al., 2000), and typography (Jacoby \& Hayman, 1987), reduce but do not eliminate priming. This finding has supported the notion that priming can be decomposed into two processes: (1) lexical operations (activation of abstract word information), which preserve priming when the physical format of the studied items changes between study and test, and (2) perceptual processes, which are responsible for producing greater priming for studied items presented at test in the same format (see Kirsner, Dunn, \& Standen, 1989).

This research was supported by Grant F32 DC00342 from NICDS. We thank the speakers who recorded the stimulus materials and the subjects who participated in this study. Correspondence concerning this article should be addressed to M. Pilotti, Department of Psychology, Hunter College, 695 Park Avenue, New York, NY 10021 (e-mail: mpilotti @ eudoramail.edu).

-Accepted by previous editorial team
Studies in which priming in healthy older adults has been examined have found either intact priming (Howard, Fry, \& Brune, 1991; Java \& Gardiner, 1991; Light, La Voie, Valencia-Laver, Albertson Owens, \& Mead, 1992; Light \& Singh, 1987; Mitchell, 1989; Moscovitch,1982) or small age-related deficits (Chiarello \& Hoyer, 1988; Davis et al., 1990; Fleischman \& Gabrieli, 1998; Hultsch, Masson, \& Small, 1991; Schacter, Church, \& Osowiecki, 1994), suggesting that this phenomenon, unlike deliberate retrieval, is largely immune to aging. Findings that overall repetition priming effects are relatively constant across age groups do not, however, unequivocally support the assumption that the processes that produce these effects are entirely age insensitive. Because evidence exists that the activation of abstract word information is spared in normal aging (Balota \& Ferraro, 1993, 1996; Karayanidis, Andrews, Ward, \& McConaghy, 1993; Spieler \& Balota, 2000), older adults' intact priming effects could be the result of an increased reliance on lexical processing, which would compensate for age-related declines in perceptual operations.

The notion that the processing of perceptual information may decline in old age comes from studies reporting that older adults cannot recollect as well as young adults all sorts of nonlinguistic features of past experiences (Kausler \& Puckett, 1981a, 1981b; Light et al., 1992; Mitchell, Hunt, \& Schmitt, 1986; Park \& Puglisi, 1985). These findings, however, may simply reflect older adults' reduced ability to retrieve information from long-term memory deliberately, without involving any specific age-related decline in either the encoding or the incidental activation at test of nonlinguistic features. Interestingly, Light et al., who examined this issue, found that although recognition memory for words and their modality of presentation declined in old age, priming in a perceptual identification test did not. Specifically, they found not only greater priming for samemodality (SM) than for different-modality (DM) studied 
words in both young and older adults, but also no reliable age-related declines in either abstract (cross-modality) or modality-specific priming. The finding of age-equivalent abstract priming corroborates the claim that lexical processing is unimpaired, although not enhanced, in old age, inasmuch as lexical information underlies this form of priming. The finding of age-equivalent modality-specific priming in the context of intact abstract priming, however, does not support the notion that perceptual processing declines in old age, inasmuch as both lexical information and perceptual features underlie modality-specific priming. Nevertheless, one could argue that modality changes are coarse alterations of the physical features of the stimulus material, and thus the possibility exists that the processing of fine-grained perceptual details might still be affected by aging. In support of this notion, Schacter et al. (1994), who examined the effects of voice changes in auditory perceptual identification and stem completion, found that these changes affected priming in young adults, but not in older adults. Specifically, young adults exhibited greater priming for words presented in the same voice (SV) at study and at test than for words presented in a different voice (DV), whereas older adults showed no extra priming benefit when there was a voice match. However, the absence of voicespecific priming in elderly adults, reported by Schacter et al., raises two questions: First, does it reflect elderly adults' deficient encoding of fine-grained perceptual features or their reduced reliance on such features at test? Second, how can it be reconciled with the finding of Sommers (1999), who reported that both young and elderly adults yielded greater priming for SV than DV studied items in perceptual identification?

Clearly, the uptake of sensory information in older adults is not only slower (see Stine, Wingfield, \& Poon, 1986; Wingfield, Poon, Lombardi, \& Lowe, 1985), but also less accurate, owing to hearing loss (Olsho, Harkins, $\&$ Lenhardt, 1985) and other peripheral impairments (Florentine et al., 1993; Konig, 1957; Moore, Peters, \& Glasberg, 1992), which reduce the overall amount of information that can be sampled from the study items (see Schneider, 1997). Thus, the possibility exists that older adults might require more exposure to a talker's voice before the perceptual details that uniquely characterize that voice can be encoded in long-term memory. Interestingly, Schacter et al. (1994) used a relatively small set of study items, as compared with that used by Sommers (1999). If our assumption is correct, a small set of studied items would unfairly penalize older adults by giving them fewer opportunities for encoding voice information, producing the null finding reported by Schacter et al. for voice-specific priming.

In the present study, we reexamined the extent to which the contribution of lexical and perceptual processes to priming may fluctuate with age. There were two major goals. The first was to assess whether we could replicate the finding of age-insensitive abstract and modality-specific priming reported by Light et al. (1992), thereby providing an additional test for the notion that lexical and coarse perceptual processes are indeed preserved in old age. The second goal was to determine whether the marked age-related declines in fine-grained perceptual processing reported by Schacter et al. (1994) could be attributed to older adults' deficient encoding of voice information. In this study, we also examined the extent to which aging modulates perceptual and lexical processes in recognition memory, so as to provide a measure of comparison for the priming data.

Auditory perceptual identification served as our implicit test. Modality of presentation (visual vs. auditory) and speaker's voice were manipulated at study so as to obtain a measure of abstract (DM), modality-specific (SM, but DV), and voice-specific (SV) priming. As in the Light et al. (1992) study, priming exhibited by words previously seen at study was assumed to reflect the extent to which abstract lexical information contributes to priming. Therefore, any reliable group difference in the magnitude of abstract priming would imply an age-related shift in the processing of this information. Modality-specific and voice-specific priming effects were assumed to reflect the contribution of both lexical and perceptual information. Therefore, in this study, larger modality-and/or voicespecific priming effects in young adults without any corresponding group difference in abstract priming would suggest an age-related decline in the processing of perceptual information. Of course, in the presence of age differences in abstract priming, the sheer magnitude of voice or modality effects would provide a measure of the extent to which perceptual processes might be affected by aging.

\section{EXPERIMENT 1 \\ Perceptual Identification With Voice Familiarization}

One of the main questions that the Schacter et al. (1994) investigation has raised is whether the finding of agerelated declines in voice-specific priming reflects elderly adults' deficient encoding of fine-grained perceptual features or their reduced reliance on such features at test. In the present experiment, we ensured that both young and older adults encoded the talkers' voices prior to the priming experiment, so that group differences in voice-specific priming could not be attributed to older adults' deficient encoding of fine-grained perceptual information.

To obtain a measure of abstract, modality-specific, and voice-specific priming at test, the subjects were assigned to one of two study conditions: hear or hear-read. In the hear condition, the subjects were presented with two lists of words, each spoken by one of the two familiar talkers. In the hear-read condition, one list involved printed words, and the other list involved words spoken by one of the familiar talkers. However, in all the study conditions, the subjects focused on the physical attributes of the study items by rating either the clarity with which spoken words were enunciated or the ease with which printed words could be read. These tasks were intended to promote the encoding of perceptual information at study, so that any 
null effect of study-to-test perceptual changes on priming could not be attributed to insufficient perceptual processing at study. Each encoding task was followed by a perceptual identification test in which studied and nonstudied words were spoken by one of the familiar talkers. Therefore, following the hear study condition, half of the studied words were presented in the same voice as at study, and half in a different voice, whereas following the hear-read study condition, half of the studied words were presented in the same voice as at study, and half in a different modality. All the test items were degraded via a lowpass filter, which made them sound muffled without significantly altering voice characteristics. Filtering was also used by Schacter et al. (1994) and Sommers (1999), whereas masking noise was used by Light et al. (1992). Therefore, filtering in the present study allowed us to ascertain whether the findings reported by Light et al. of intact abstract and modality-specific priming in the aged could be replicated with a different form of stimulus degradation. In the present study, there were also two test conditions. In the equal-degradation(E-D) condition, the same level of stimulus degradation was adopted for young and older subjects, whereas in the different-degradation(D-D) condition, stimulus degradation varied between age groups, with older adults receiving less degraded stimuli than did young adults. The D-D condition served to control baseline performance for differences between age groups, thereby ruling out the possible contribution of these differences to the priming effects observed in the other condition.

\section{Method}

Subjects. Sixty-four young adults and 64 older adults participated in this experiment (16 young and 16 older adults were assigned to each between-subjects condition). Young adults' mean age was 20.05 years (18-25), and their mean vocabulary score was 32.33 $(S D=2.34)$. Older adults' mean age was 74.82 years $(65-86)$, and their mean vocabulary score was $32.85(S D=2.84)$. The vocabulary scores (Shipley, 1940) of the two subject groups were not reliably different $[t(126)=1.12]$. The young adults were Washington University undergraduate students, who participated in the experiment for course credit. The older adults were community members from the Washington University Aging and Development Subject Pool, who were paid for participating in the experiment. All the subjects reported themselves as being in a healthy condition for their age.

Because a major concern in comparing performance of young and elderly adults on auditory tests is the decreased hearing acuity of the aged, pure-tone air conduction thresholds for octave frequencies from 250 to $4000 \mathrm{~Hz}$ were collected from all the subjects. Hearing acuity served as a gross measure of age-related declines in sensory uptake that could be used to account for age differences in priming, if such differences were detected in test performance. Average puretone air conduction thresholds for the better ear and standard errors of the mean $(S E M)$ are reported in Figure 1. There are two major points to note from this figure: First, young adults' thresholds for all the selected frequencies were below $20 \mathrm{~dB}$, which is the threshold that defines normal hearing for young adults according to the American National Standards Institute. Second, although hearing acuity declined with age across all the selected frequencies $[F(1,126)=$ $\left.370.30, M S_{\mathrm{e}}=158.82\right]$, high-frequency information yielded the largest declines $\left[F(4,504)=97.99, M S_{\mathrm{e}}=58.04 ; p s<.05\right]$.

Stimuli and Apparatus. The stimuli for all the experiments were selected from a set of 300 bisyllabic and trisyllabic English words (see Pilotti et al., 2000). The words were either low or medium frequency $(M=9.4, S D=14.8$; Kučera $\&$ Francis, 1967) and were all highly familiar $(M=6.7 ; S D=0.57$; Nusbaum, Pisoni, \& Davis, 1984). Two talkers, one male and one female, recorded all the stimuli. Two other talkers, one male and one female, also recorded the 20 stimuli of the voice discrimination phase (explained below).

The stimuli of the study phase were selected from this set so as to make up four study lists of 36 words matched for frequency and familiarity (frequency, $M=8.7, S D=13.7$; familiarity, $M=6.7$, $S D=0.6$ ). The 72 stimuli of the voice familiarization phase and the 20 stimuli of the voice discrimination phase were selected from the remaining stimuli. Three versions of each study list were devised: words spoken in either a male or a female voice or printed in an irregular font (Florentine). The test list included 10 filler words and 144 randomly presented words (72 studied and 72 nonstudied). A Latin-square design was used to counterbalance the pairing of study lists, the assignment of talkers and input modality to study lists, and the assignment of talkers to the test list, so as to create 16 unique combinations of study and test lists.

The auditory stimuli were digitized at a sampling rate of $20 \mathrm{kHz}$, and their amplitude levels were digitally equated using a software package specif ically designed to modify speech waveforms. The stimuli were presented over headphones at an $80-\mathrm{dB}$ sound pressure level via an IBM-compatible computer equipped with a 16-bit digital-to-analog converter.

Procedure and Design. The experiment consisted of five phases: a voice familiarization session, a voice discrimination test, a study phase, a 5-min break, and a test phase. The voice familiarization phase involved two blocks of 72 trials. The same 72 words were used in each block, so that the subjects heard two instances of every word, one spoken in a male voice and the other spoken in a female voice. On each trial, the name of one of the talkers (Mary or Paul) appeared in the center of the computer screen $1 \mathrm{sec}$ before the onset of a spoken word and remained on the screen for $2.5 \mathrm{sec}$. A 1-sec blank screen separated consecutive trials. The subjects were instructed to become familiar with each speaker's voice so as to prepare themselves for the next phase of the experiment, which involved discriminating between familiar and novel voices. During the voice discrimination test, the subjects heard 20 words randomly presented, half produced by the two familiar talkers (Mary and Paul) and half produced by two novel talkers (a male and a female). On any given trial, their task was to indicate whether the voice was old or new by pressing one of two keys on the computer keyboard, appropriately labeled as "O" and "N." They received feedback on each trial. All the subjects reached an accuracy level of at least $90 \%$ on the discrimination test before entering the next phase of the experiment. A large number of older adults (83\%), but none of the young adults, had to repeat the familiarization phase before reaching this level of accuracy. Four elderly subjects who could not reach the criterion were eliminated from the study.

During study, the subjects were presented with two blocks of 36 trials. Each trial consisted of a 500-msec blank screen, a 150-msec tone serving as a warning signal, a visually presented number labeling the trial, a 500-msec blank screen, and a stimulus word presented either visually or auditorily. A trial ended and the next trial began $8 \mathrm{sec}$ after stimulus presentation. There were two between-subjects study conditions, all involving incidental encoding: hear and hearread. In the hear condition, the words of one block were spoken by the familiar male talker (Paul), and those of the other block were spoken by the familiar female talker (Mary). On any given trial, the subjects were asked to rate how clearly the talker pronounced the word of that trial on a 7-point scale (from $1=$ very unclear to $7=$ very clear). In the hear-read condition, one block contained words printed in Florentine font, and the other block contained words spoken by one of the familiar talkers. On each trial of the block including printed words, the subjects were asked to rate how easy it was to read a printed word on a 7 -point scale (from $7=$ very easy to $1=$ 

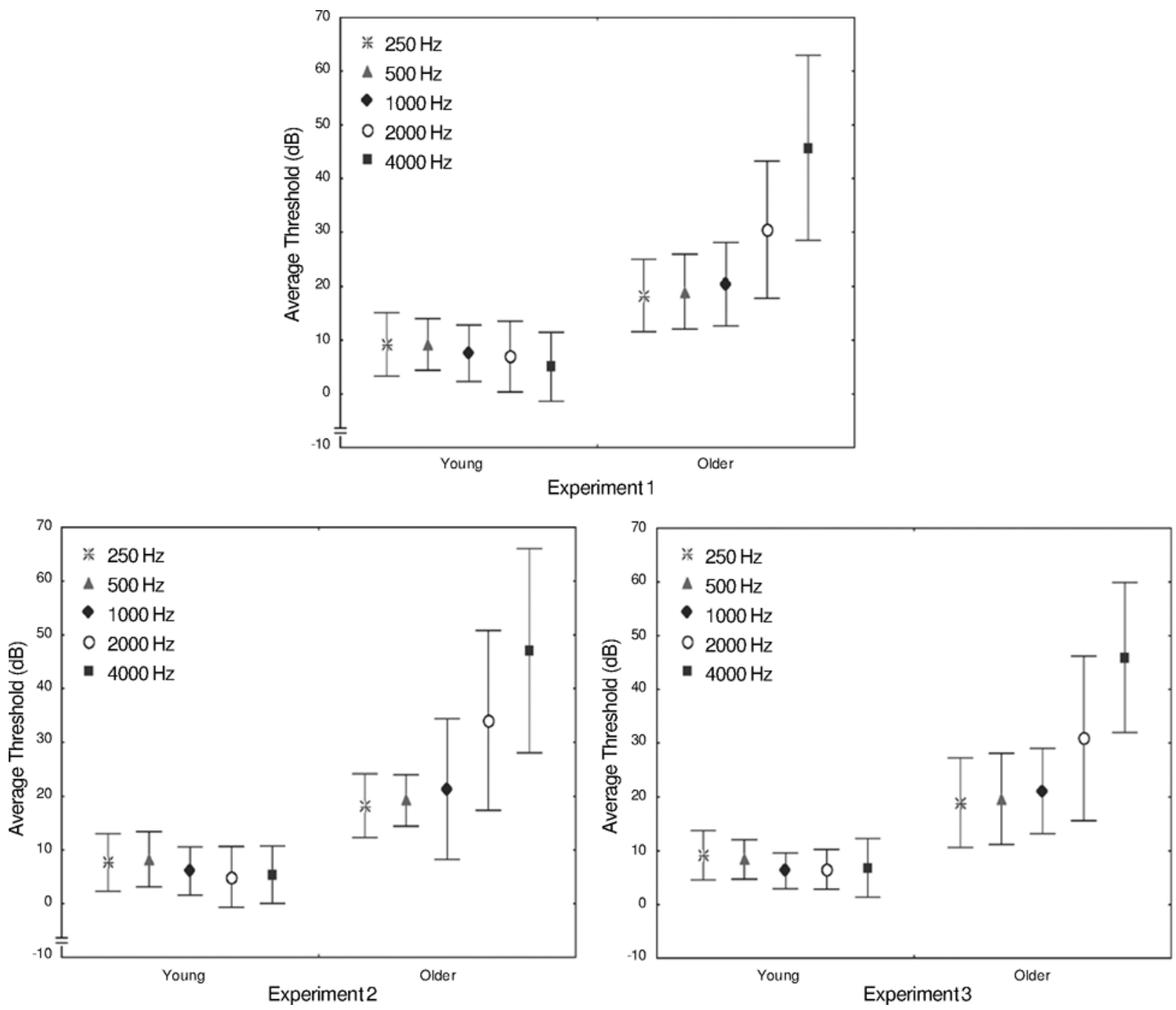

Figure 1. Experiments 1-3: Average thresholds and SEMs (dB) of young and older participants' better ear for octave frequencies from 250 to $4000 \mathrm{~Hz}$.

very difficult). On each trial of the other block, the subjects were asked to rate how clearly the talker pronounced the word of that trial on the scale used in the hear condition. All the subjects were given a two-page booklet to record their answers.

The test block included 10 filler trials placed at the beginning of the block and 144 randomly presented word trials (72 studied words and 72 nonstudied words). The subjects pressed the Enter key to begin each trial. A trial consisted of a 500-msec blank screen, a 150msec tone serving as a warning signal, a visually presented number labeling the trial, a 500-msec blank screen, and a low-pass-filtered word. The subjects were instructed to identify the test items and report their responses in a booklet with 154 numbered blanks. Half of the subjects heard stimuli spoken by the familiar male talker, and the other half heard stimuli spoken by the familiar female talker. Therefore, following the hear study condition, half of the studied words were always spoken at test in the same voice as at study, and half were spoken in a different voice. In contrast, following the hearread study condition, half of the words were spoken in the same voice as at study, and half involved a modality change (visual pre- sentation at study and auditory presentation at test). There were two test conditions. In the E-D condition, the test words were low-pass filtered at $1 \mathrm{kHz}$ (i.e., frequencies above $1 \mathrm{kHz}$ were eliminated from the speech stimuli) for all the subjects. In the D-D condition, the test words were low-pass filtered at $0.8 \mathrm{kHz}$ for young adults and at $1.6 \mathrm{kHz}$ for older adults (i.e., older adults received less degraded stimuli than did young adults). Pilot testing indicated that these levels of low-pass filtering roughly equated baseline identification rates (nonstudied words) between young and older adults.

A mixed factorial design was used in this experiment. Age (young vs. old), study condition (hear vs. hear-read), and degradation condition (E-D vs. D-D) were the between-subjects factors. Item type (same-format studied vs. different-format studied vs. nonstudied words) was the within-subjects factor.

\section{Results and Discussion}

Tables 1-2 display the priming scores and the proportions of nonstudied items identified at test (baseline). In 
Table 1

Equal Degradation Test Condition: Priming Scores, Proportions of Nonstudied Words Identified in the Auditory Implicit Test, and $S E M s$ in Experiment 1

\begin{tabular}{|c|c|c|c|c|c|c|c|}
\hline \multirow[b]{2}{*}{ Study } & \multirow[b]{2}{*}{ Age } & \multicolumn{2}{|c|}{$\begin{array}{c}\text { SV } \\
\text { Priming }\end{array}$} & \multicolumn{2}{|c|}{$\begin{array}{l}\text { SM/DV } \\
\text { Priming }\end{array}$} & \multicolumn{2}{|c|}{$\begin{array}{c}\text { NS Proportion } \\
\text { Correct } \\
\end{array}$} \\
\hline & & $M$ & $S E M$ & $M$ & $S E M$ & $M$ & SEM \\
\hline \multirow[t]{4}{*}{ Hear } & young & +.17 & .02 & +.11 & .02 & .27 & .02 \\
\hline & older & +.17 & .03 & +.11 & .02 & .16 & .02 \\
\hline & & \multicolumn{2}{|c|}{$\begin{array}{c}\text { SV } \\
\text { Priming }\end{array}$} & \multicolumn{2}{|c|}{$\begin{array}{c}\text { DM } \\
\text { Priming }\end{array}$} & \multicolumn{2}{|c|}{$\begin{array}{c}\text { NS Proportion } \\
\text { Correct }\end{array}$} \\
\hline & & $M$ & SEM & $M$ & SEM & $M$ & SEM \\
\hline \multirow[t]{2}{*}{ Hear-Read } & young & +.17 & .03 & +.03 & .02 & .27 & .02 \\
\hline & older & +.16 & .01 & +.05 & .01 & .16 & .01 \\
\hline
\end{tabular}

Note-SV, same voice; SM/DV, same modality/different voice; DM, different modality; NS, nonstudied.

these tables, the proportion of studied items identified at test can be computed by adding the priming scores to the baseline rates. There are three major points to note from Tables 1-2: First, the two degradation conditions produced equivalent amounts of priming, which suggested that baseline differences in the E-D condition did not conceal differences in the magnitude of priming. Second, priming increased as a function of study-to-test physical similarity, indicating that priming was sensitive to perceptual information in both age groups. Third, young and older adults did not produce notably different amounts of abstract priming (DM priming), modality-specific priming (SM/DV priming), and voice-specific priming (SV priming). These observations were supported by the analyses reported below. All the results reported here and in the following experiments are reliable at the .05 level, unless otherwise specified.

The first set of analyses involved assessing whether the manipulation of degradation levels achieved its aim of equating baseline rates (identification scores for nonstudied words) between the two age groups. As was expected, in the E-D condition, young adults' identification rates were higher than those of elderly subjects $[F(1,62)=$ $\left.38.79, M S_{\mathrm{e}}=0.005\right]$, whereas, in the D-D condition, baseline rates were not reliably different $(F=2.16)$.

The second set of analyses examined whether priming varied as a function of age, study condition, item type, and degradation level. ${ }^{1}$ In the hear condition, a 2 (young vs. old) $\times 2$ (same format vs. different format) $\times 2$ (E-D vs. D-D) analysis of variance (ANOVA) illustrated that SV priming was greater than SM/DV priming $\left[F(1,60)=60.83, M S_{\mathrm{e}}=\right.$ 0.003 ; other $\left.F_{\mathrm{s}}<1\right]$. In the hear-read condition, the same analysis showed that SV priming was greater than DM priming $\left[F(1,60)=313.14, M S_{\mathrm{e}}=0.001\right.$; other $\left.F \mathrm{~S}<2.95\right]$. As was expected, SM/DV priming was also greater than $\mathrm{DM}\left(\right.$ abstract) priming $\left[F(1,126)=19.61, M S_{\mathrm{e}}=0.005\right]$. Therefore, the magnitude of priming increased with studyto-test physical similarity in both young and older adults, suggesting that, in this experiment, the subjects yielded abstract, modality-specific, and voice-specific priming, which did not differ across age groups and degradation conditions.

The absence of age differences in either abstract or modality-specific priming observed in our experiment replicates the finding of Light et al. (1992), whereas the absence of age differences in voice-specific priming conflicts with the finding of Schacter et al. (1994). However,

Table 2

Different-Degradation Test Condition:

Priming Scores, Proportions of Nonstudied Words Identified in the Auditory Implicit Test, and SEMs in Experiment 1

\begin{tabular}{|c|c|c|c|c|c|c|c|}
\hline \multirow[b]{2}{*}{ Study } & \multirow[b]{2}{*}{ Age } & \multicolumn{2}{|c|}{$\begin{array}{c}\text { SV } \\
\text { Priming } \\
\end{array}$} & \multicolumn{2}{|c|}{$\begin{array}{l}\text { SM/DV } \\
\text { Priming } \\
\end{array}$} & \multicolumn{2}{|c|}{$\begin{array}{c}\text { NS Proportion } \\
\text { Correct } \\
\end{array}$} \\
\hline & & $M$ & SEM & $M$ & SEM & $M$ & $S E M$ \\
\hline \multirow[t]{4}{*}{ Hear } & young & +.18 & .02 & +.10 & .01 & .22 & .01 \\
\hline & older & +.19 & .02 & +.11 & .02 & .20 & .01 \\
\hline & & \multicolumn{2}{|c|}{$\begin{array}{c}\text { SV } \\
\text { Priming } \\
\end{array}$} & \multicolumn{2}{|c|}{$\begin{array}{c}\mathrm{DM} \\
\text { Priming }\end{array}$} & \multicolumn{2}{|c|}{$\begin{array}{c}\text { NS Proportion } \\
\text { Correct } \\
\end{array}$} \\
\hline & & $M$ & $S E M$ & $M$ & SEM & $M$ & $S E M$ \\
\hline \multirow[t]{2}{*}{ Hear-Read } & young & +.19 & .02 & +.06 & .02 & .21 & .01 \\
\hline & older & +.17 & .02 & +.06 & .02 & .20 & .01 \\
\hline
\end{tabular}

Note-SV, same voice; SM/DV, same modality/different voice; DM, different modality; NS, nonstudied. 
even though young and older adults yielded equivalent voice-specific priming effects in our experiment, $83 \%$ of the older adults needed considerably more training with the voices of the familiarization session before reaching the criterion of at least $90 \%$ correct on the discrimination test. Elderly adults' difficulties in the discrimination test might have reflected their reduced ability to retrieve information from long-term memory intentionally. However, these difficulties might have also reflected age-related declines in the uptake of sensory information, which disrupted the processes that extract the features of novel voices from acoustic signals. Of course, the latter account would provide a reasonable explanation for the lack of voice-specific priming in the aged reported by Schacter et al. Specifically, one could argue that the study lists of Schacter et al., which included only 24 words, each spoken by one of six talkers, might have not given older adults enough exposure to each voice, preventing them from encoding voice characteristics. Experiment 2 put this account to the test.

\section{EXPERIMENT 2 \\ Perceptual Identification Without Voice Familiarization}

In Experiment 2, we examined whether older adults would preserve their ability to produce voice-specific priming without any voice familiarization training. As was discussed above, there were at least two reasons for raising this question. First, the voice discrimination test of Experiment 1 consistently indicated that older adults required more exposure to the voices of the familiarization phase before being able to identify them. Second, Schacter et al. (1994) did not find voice-specific priming in an experimental procedure that did not include a voice familiarization phase and involved a relatively small study set with six voices. If aging affects the processes that extract the features of novel talkers' voices from acoustic signals, excluding the voice familiarization phase from the priming experiment should reduce or eliminate voicespecific priming in elderly adults. To test this hypothesis, in Experiment 2, we exposed young and older subjects to the hear study condition and the perceptual identification test of Experiment 1 without prior voice training.

\section{Method}

Subjects. Thirty-two young adults and 32 older adults participated in this experiment (16 per between-subjects condition). Young adults' mean age was 21.28 years (18-29), and their mean vocabulary score was $32.16(S D=2.89)$. Older adults' mean age was 75.78 years $(65-87)$, and their mean vocabulary score was $32.91(S D=3.29)$. The two groups did not reliably differ in vocabulary scores $(t<1)$. The subjects were recruited from the same subject pools as those used for Experiment 1. Figure 1 reports average pure-tone air conduction thresholds for the better ear. As in the earlier experiment, young adults' thresholds were below $20 \mathrm{~dB}$, and hearing acuity decreased with age across all the selected frequencies $[F(1,62)=$ $148.49, M S_{\mathrm{e}}=249.49$ ], with high-frequency information yielding the largest age-group differences $\left[F(4,248)=46.08, M S_{\mathrm{e}}=32.45\right]$.

Materials and Procedure. The subjects performed the clarityrating task (hear study condition) and then the perceptual identification test of Experiment 1 without prior voice familiarization. As in the earlier experiment, the perceptual identification task was administered under the E-D and the D-D conditions, with half of the words spoken in the same voice as at study and half in a different voice. To assess whether the elderly subjects of this experiment were comparable to those of Experiment 1 with respect to voice identification, the voice familiarization phase and the discrimination test described earlier were administered either after the perceptual identification test or in a separate session. Both involved voices never presented during the priming experiment. As in Experiment 1, none of the young adults, but the majority of the older adults $(82 \%)$, had to repeat the familiarization phase to reach the criterion of at least $90 \%$ correct on the discrimination test.

\section{Results and Discussion}

Table 3 displays the priming scores and the proportions of nonstudied items identified at test. There are two major points to note from this table. First, the E-D and the D-D conditions did not yield different amounts of priming. Second, young and older adults did not produce different amounts of modality-specific priming (SM/DV priming). Young adults, however, displayed voice-specific priming (SV priming), whereas older adults did not. These observations were supported by the analyses reported below.

As in Experiment 1, we first assessed the effects of manipulating degradation levels at test on baseline identification rates. As was expected, in the E-D condition, young adults displayed higher baseline identification rates than did the elderly subjects $\left[F(1,30)=9.80, M S_{\mathrm{e}}=0.006\right]$, whereas, in the D-D condition, baseline rates were not reliably different $(F=1.37)$.

The second set of analyses examined whether priming varied as a function of age, item type, and degradation level (see note 1). A 2 (young vs. old) $\times 2$ (same format vs. different format) $\times 2$ (E-D vs. D-D) ANOVA yielded a marginally significant effect of age $\left[F(1,60)=3.45, M S_{\mathrm{e}}=\right.$ $0.01, p=.07]$ and a main effect of item type $[F(1,60)=$

Table 3

Priming Scores, Proportions of Nonstudied Words Identified in the Auditory Implicit Test, and SEMs in Experiment 2

\begin{tabular}{|c|c|c|c|c|c|c|c|c|}
\hline \multirow[b]{2}{*}{ Condition } & \multirow[b]{2}{*}{ Study } & \multirow[b]{2}{*}{ Age } & \multicolumn{2}{|c|}{$\begin{array}{c}\text { SV } \\
\text { Priming }\end{array}$} & \multicolumn{2}{|c|}{$\begin{array}{l}\text { SM/DV } \\
\text { Priming }\end{array}$} & \multicolumn{2}{|c|}{$\begin{array}{c}\text { NS Proportion } \\
\text { Correct }\end{array}$} \\
\hline & & & $M$ & $S E M$ & $M$ & $S E M$ & $M$ & $S E M$ \\
\hline \multirow[t]{2}{*}{ E-D test } & hear & young & +.17 & .02 & +.11 & .03 & .26 & .03 \\
\hline & hear & older & +.10 & .02 & +.11 & .02 & .17 & .01 \\
\hline \multirow[t]{2}{*}{ D-D test } & hear & young & +.18 & .02 & +.12 & .02 & .21 & .01 \\
\hline & hear & older & +.11 & .02 & +.12 & .01 & .19 & .01 \\
\hline
\end{tabular}

Note-SV, same voice; SM/DV, same modality/different voice; NS, nonstudied. 
$\left.16.01, M S_{\mathrm{e}}=0.001\right]$. This analysis also yielded a reliable interaction of age and item type $\left[F(1,60)=27.92, M S_{\mathrm{e}}=\right.$ $0.001]$, which illustrated an age difference in subjects' sensitivity to study-to-test physical similarity (other $F \mathrm{~s}<1$ ). Young adults yielded greater SV priming than SM/DV priming $\left[F(1,62)=12.57, M S_{\mathrm{e}}=0.006\right]$. As in the Schacter et al. (1994) investigation, older adults displayed equivalent SV and SM/DV priming $(F<1)$, thereby yielding no evidence of voice-specific priming. Statistically removing the effect of age differences in hearing acuity from SV priming via an analysis of covariance preserved the effect of age $(F=9.72)$. Interestingly, Schacter et al. did not find voice-specific priming in elderly adults with either hearing losses or hearing acuity comparable to that of young subjects. Thus, in our experiment and in the Schacter et al. investigation, hearing acuity, serving as a gross measure of elderly adults' reduced uptake of sensory information, did not account for age-related declines in voice processing.

\section{EXPERIMENT 3 Recognition Memory}

The results of Experiments 1-2 demonstrated that when the encoding of lexical information and perceptual details is ensured at study, both young and older adults rely on these different forms of information in the implicit test of perceptual identification. Considerable evidence, however, exists that deliberate retrieval of all sorts of information regarding earlier experiences declines in old age. For example, older adults are generally less accurate in remembering which words they studied (Light \& Singh, 1987; Schacter et al., 1994) and whether these words were presented auditorily or visually, in a male or female voice, or in uppercase or lowercase letters (Kausler \& Puckett, 1980, 1981a, 1981b). Thus, we predicted that older adults' recognition memory would be overall less accurate, providing evidence for a dissociation of implicit and explicit measures of memory. In Experiment 3, we put this hypothesis to the test by comparing recognition memory in young and older adults who had been exposed to the voice familiarization session, discrimination test, and the study conditions of Experiment 1.

In this experiment, study-to-test format changes permitted us to assess whether deliberate retrieval relies on perceptual information. Whether input modality and voice would dissociate implicit and explicit measures in young adults, however, was largely a matter of empirical investigation. Indeed, conflicting findings exist with respect to whether recognition memory is sensitive to perceptual information in young adults, with some studies reporting no effect of modality or voice changes (e.g., Church \& Schacter, 1994; Craik, Moscovitch, \& McDowd, 1994; Schacter $\&$ Church, 1992) and others reporting that such changes hurt recognition memory (Goldinger, 1996; Hintzman, Block, \& Inskeep, 1972; Kirsner, 1974; Palmeri, Goldinger, \& Pisoni, 1993). Therefore, the extent to which study-totest physical changes would affect recognition memory in young adults provided the basis for assessing whether age differences exist in subjects' reliance on perceptual cues during deliberate recollection.

\section{Method}

Subjects. Thirty-two young adults and 32 older adults participated in this experiment (16 young and 16 older adults were assigned to each study condition). Young adults' mean age was 20.38 years (18-27), and their mean vocabulary score was $32.13(S D=$ 3.09). Older adults' mean age was 74.44 years $(65-88)$, and their mean vocabulary score was $32.53(S D=3.11)$. The two groups did not reliably differ in vocabulary scores $[t(62)<1]$. The subjects were recruited from the same subject pools as those used for Experiments 1-2. Average pure-tone air conduction thresholds for the better ear are reported in Figure 1. As in the earlier experiments, young adults' thresholds for all the selected frequencies were below $20 \mathrm{~dB}$. Furthermore, hearing acuity decreased with age across all the selected frequencies $\left[F(1,62)=215.95, M S_{\mathrm{e}}=145.87\right]$, with high-frequency information yielding the largest age-group differences $[F(4,248)=$ 44.29, $\left.M S_{\mathrm{e}}=53.45\right]$.

Materials and Procedure. The stimulus materials and the experimental phases were as described for the hear and hear-read conditions of Experiment 1, with the exception that a recognition task was administered at test. As in the earlier experiments, a large number of older adults ( $83 \%$ ) had to repeat the familiarization phase to reach the criterion of at least $90 \%$ correct on the discrimination test. Prior to the recognition memory test, the subjects were told that words presented in the clear (i.e., without degradation) would be spoken over the headphones. Their task was to indicate which words had been presented during the earlier study phase and to report their answers in a booklet with 154 numbered blanks. To minimize agegroup differences in response criterion and the influence of implicit processes at test, the subjects were encouraged to use a conservative response criterion to decide whether any given item was a studied word.

\section{Results and Discussion}

Corrected recognition scores (the proportion of studied words recognized as old minus the proportion of nonstudied words falsely identified as old) and false alarm rates (proportion of nonstudied words falsely identified as old) are shown in Table 4. There are two major points to note from Table 4. First, although young adults exhibited better recognition memory, in both age groups, false alarm rates were considerably low, indicating that young and older adults adopted an equally conservative response criterion. Second, young adults' recognition memory was sensitive to modality changes, but not to voice changes, whereas older adults' recognition memory was impaired across all

Table 4

Corrected Recognition Scores, False Alarms, and $S E M$ s in Experiment 3

\begin{tabular}{|c|c|c|c|c|c|c|c|}
\hline \multirow[b]{2}{*}{ Study } & \multirow[b]{2}{*}{ Age } & \multicolumn{2}{|c|}{ SV } & \multicolumn{2}{|c|}{ SM/DV } & \multicolumn{2}{|c|}{ FA } \\
\hline & & $M$ & $S E M$ & $M$ & $\overline{S E M}$ & $M$ & SEM \\
\hline \multirow[t]{4}{*}{ Hear } & young & .67 & .03 & .69 & .02 & .08 & .03 \\
\hline & older & .13 & .02 & .14 & .02 & .09 & .01 \\
\hline & & \multicolumn{2}{|c|}{ SV } & \multicolumn{2}{|c|}{ DM } & \multicolumn{2}{|c|}{ FA } \\
\hline & & $\bar{M}$ & $\overline{S E M}$ & $M$ & $\overline{S E M}$ & $M$ & $\overline{S E M}$ \\
\hline \multirow[t]{2}{*}{ Hear-read } & young & .65 & .04 & .56 & .04 & .07 & .01 \\
\hline & older & .12 & .02 & .12 & .01 & .08 & .01 \\
\hline
\end{tabular}

Note-SV, same voice; SM/DV, same modality/different voice; DM, different modality; FA, false alarm. 
the study-to-test conditions. These observations were supported by the analyses reported below.

A 2 (young vs. old) $\times 2$ (same- vs. different-format item) $\times 2$ (hear vs. hear-read) ANOVA was conducted on the corrected recognition scores to assess the effect of age and format changes on recognition memory. In this analysis, there was a main effect of age $[F(1,60)=463.11$, $\left.M S_{\mathrm{e}}=0.02\right]$, which denoted young adults' superior recognition memory. Item type interacted with age $[F(1,60)=$ $\left.5.39, M S_{\mathrm{e}}=0.003\right]$, with study condition $[F(1,60)=11.29$, $\left.M S_{\mathrm{e}}=0.003\right]$, and with both age and study condition $\left[F(1,60)=9.81, M S_{\mathrm{e}}=0.003\right]$. The latter interaction revealed that young adults' recognition memory decreased with modality changes $\left[F(1,15)=12.50, M S_{\mathrm{e}}=0.006\right]$ but was unaffected by voice changes $(F=1.3)$, whereas older adults' recognition memory was considerably impaired for both same- and different-format items $\left(F_{\mathrm{S}}<1.2\right)$.

A 2 (young vs. old) $\times 2$ (hear vs. hear-read) ANOVA conducted on the false alarm rates did not yield any reliable effects $(F \mathrm{~s}<3.3)$. Thus, false alarm rates were not only relatively low, but also not reliably different between age groups. This finding indicated that both young and older adults used a conservative response criterion, which discouraged guessing and thus minimized the influence of incidental retrieval processes ( judgments based on familiarity) on recognition memory. As a result, implicit and explicit memory performance could be empirically dissociated in our study. Indeed, we found that, in young adults, priming effects were sensitive to both voice and modality changes, but recognition memory was sensitive only to modality changes. Furthermore, age had a detrimental effect on recognition memory but left priming virtually intact when a voice familiarization session preceded the encoding phase (see Experiment 1). Older adults' impaired recognition memory across all the study-to-test conditions may be interpreted as just another example of the age-related declines in deliberate recollection that have been documented in other investigations (Light et al., 1992; Schacter et al., 1994; Sommers, 1999). However, the corrected recognition scores of our older adults were considerably lower than those reported by Schacter et al. and Sommers following a clarityrating encoding task, whereas they were not very different from those found by Light et al. following a syllable-count task. Furthermore, in our experiment, older adults yielded not only lower false alarm rates than in any of these other investigations, but also false alarm rates equivalent to those exhibited by young adults. Thus, the possibility exists that older adults' impaired recognition memory might have been due to both our perceptually driven encoding task and our test instructions, which were intended to minimize the influence of responses driven by implicit processes (familiarity). Not surprisingly, under these instructions, older adults' performance was poor in all the study-to-test conditions, supporting the notion that when the influence of implicit processes is minimized at test, older adults' deliberate retrieval of all sorts of information becomes considerably impaired.

\section{GENERAL DISCUSSION}

The findings of this study, in which age differences in repetition priming and recognition memory in auditory tests were examined, can be summarized in three main points. First, in the implicit test of perceptual identification, young and older adults, who had familiarized themselves with the study and test voices prior to the experiment, displayed equivalent amounts of abstract, modalityspecific, and voice-specific priming. Second, although older adults displayed voice-specific priming effects in perceptual identification, they required additional training with the study voices before being able to encode these voices in long-term memory (as was demonstrated by the scores of the voice discrimination test). Furthermore, without prior voice familiarization, older adults did not display voice-specific priming. Third, age yielded a clear dissociation between perceptual identification and recognition memory. Older adults performed more poorly on the recognition test than did young adults across all the study-to-test conditions, whereas there were no age differences in priming (see Experiment 1). Furthermore, with respect to young adults, voice changes yielded a clear dissociation between perceptual identification and recognition memory, influencing priming, but not recognition memory.

The results of these experiments have important implications not only for understanding the role of perceptual and lexical processes in memory, but also for clarifying the effects of aging on these processes. Specifically, the finding of voice- and modality-specific priming in the auditory perceptual identification test of Experiment 1 supports the notion that both young and older adults can encode perceptual attributes at study and that these attributes promote priming. This finding is consistent with hybrid models of memory, in which perceptual details and abstract linguistic information are assumed to involve separate but connected memory representations, in the same way as the context in which an event has occurred is connected with the event itself in memory (see MacKay, 1992; Schacter \& Church, 1992). According to these models, the priming effects observed in the present study depend on three sequentially organized processes. First, subjects gather from each of the study words linguistic and perceptual information. Second, they preserve these two qualitatively different forms of information in separate but associated memory representations. Third, assuming that the memory test engages perceptual operations (see Roediger, Weldon, \& Challis, 1989), subjects reactivate these memory representations at the time of test. Because lexical information concerning each studied word is linked to its perceptual context in memory, priming is expected to be greater for words presented at test in the same format as at study than for words involving a format change (as we have observed in Experiment 1). In hybrid models, the voice familiarization session of our investigation can be conceptualized as giving 
subjects the opportunity to encode in long-term memory information about the voices of the speakers who will utter the study words of the priming experiment. Therefore, voice information preserved in memory can be expected to facilitate the processes involved in extracting this information from the study words. In our investigation, young adults yielded voice-specific priming with or without prior voice familiarization. In contrast, older adults exhibited voice-specific priming only after voice familiarization and had more difficulty in identifying the familiar voices of the discrimination test. Hybrid models can account for these findings by assuming that the processes that extract voice information from spoken words are somewhat compromised in old age.

Our finding of modality- and voice-specific priming in the perceptual identification test of Experiment 1 is also consistent with episodic memory models, which assume that lexical information and perceptual details yield unitary, rather than distinct, memory representations (Goldinger, 1996, 1998; Hintzman, 1986). These models postulate that each study word generates a distinct representation including lexical information and perceptual details. Therefore, greater priming for same-format studied words than for words involving format changes would depend on the activation of episodic representations at the time of test. These episodic models, like the hybrid models discussed earlier, can account for the finding that older adults exhibited voice-specific priming only after voice familiarization by assuming that older adults are less adept at extracting voice characteristics from speech signals. Of course, this assumption involves conceptualizing episodic traces not as mere analogues of incoming stimuli, but as complex entities defined by both the physical form of the stimuli and the operations that subjects perform upon them (Van Orden \& Goldinger, 1994). Consequently, in these episodic models, the assumption of age-related declines in voice processing would lead us to expect that the multitude of memory representations generated during the familiarization session, whose common and distinct voice features symbolize subjects' knowledge of each talker's voice, would be less voice specific in elderly adults. With increased exposure to each voice during the familiarization session, however, we would also expect these representations to become as voice specific as those of young adults and, thus, facilitate the processing of voice information at study. The results of Experiments 1-2 support these predictions.

Our findings not only are consistent with both episodic and hybrid models, but also provide a reasonable explanation for the absence of voice-specific priming in older adults reported by Schacter et al. (1994). As was discussed above, Schacter et al. used a priming procedure involving the encoding and implicit tasks of Experiments 1-2 but a much smaller number of study items ( 24 study items spoken by six different talkers). Our findings suggest that elderly adults under specific experimental conditions may fail to gather voice information from the stimulus material of the study phase, which in turn makes this information unavailable at test. We have proposed that the exper- imental design used by Schacter et al. may have not given older adults enough exposure to each of the study voices, thus preventing the encoding of voice characteristics at study. Consistent with this notion, Sommers (1999), who found voice-specific priming in older adults without prior voice familiarization, used a much larger number of study items. However, even in this investigation, there were small age-related declines in voice-specific priming, which surface when one attempts to control for agegroup differences in baseline performance via the computation of relative priming scores (Snodgrass \& Feenan, 1990). Of course, because the Sommers investigation involved a smaller number of items per study voice than did ours and did not provide older adults with voice familiarization training, this pattern of results is not surprising. Interestingly, Gibson, Brooks, Friedman, and Yesavage (1993), who examined the effects of study-to-test typefont changes on visual stem completion priming with baseline performance equated between age groups, found greater priming for same-typeface than for different-typeface studied words in both young and older adults (Experiments $2 \mathrm{a}$ and $2 \mathrm{~b}$ ). However, in this study, typefont-specific priming effects were observed only when subjects counted syllables at study, but not when they searched for a specified letter, albeit one would expect the letter-search task to afford as much visual processing as the syllable-count task. Surprisingly, older adults exhibited typefont-specific priming effects comparable to those of young adults, even though the study set contained only 32 items printed in two different typefonts. The task-dependent nature of these priming effects suggests that extensive exposure to finegrained perceptual information may not be the only means for enhancing perceptual processing in the aged. As was discussed earlier, memory representations are complex entities defined by both the physical form of the stimuli and the encoding operations that subjects perform upon them. Consequently, older adults' difficulties in extracting fine-grained information from the stimulus material may be attenuated not only by sufficient exposure to finegrained perceptual details at study, but also by encoding tasks and stimulus materials that can promote older adults' attention at study. With respect to this proposal, it is important to note that the set of items used by Schacter et al. (1994) not only was quite small, but also involved items derived from six semantic categories. A stimulus material that can be easily organized into semantic categories, however, may lead subjects to devote less attention (processing) to each of the study items. Because the uptake of sensory information is reduced in old age, less attention devoted to the study items may prevent elderly adults from encoding even the most rudimentary form of voice information, thus eliminating voice-specific priming in the aged (as was reported by Schacter et al.). In contrast, Sommers (1999) used monosyllabic words, which, given elderly adults' slower uptake of sensory information, are more difficult to process than the polysyllabic words used by Schacter et al. and in our investigation. Processing difficulty is likely to enhance attention at study, 
which may in turn ameliorate the uptake of sensory information in older adults, producing the voice-specific priming effects reported by Sommers.

Although age-related declines in the uptake of sensory information appear to be the likely culprit for the absence of voice-specific priming in the elderly adults of Experiment 2, we found no direct evidence that elderly adults' lower hearing acuity could account for this finding (see also Schacter et al., 1994). There are, however, several other factors (e.g., slowing, and declines in frequency, temporal, and intensity discrimination; see Florentine et al., 1993; Konig, 1957; Moore et al., 1992; Schneider, 1997; Stine et al., 1986), which, independently of losses in pure-tone sensitivity, can limit and/or disrupt the uptake of sensory information in old age. Thus, these factors, rather than hearing acuity, may directly affect the processing of fine-grained perceptual information and, as a result, account for the absence of voice-specific priming in the elderly adults of Experiment 2. Of course, one may ask whether age-related declines in the uptake of sensory information lead older adults to adopt a mode of processing for word items that discards fine-grained perceptual details and places a premium on linguistic information. In Experiment 1, as in the Light et al. (1992) study, we found no evidence of age differences in abstract priming. In these experiments, however, the magnitude of abstract priming was quite modest. Thus, it is possible that other stimulus materials and/or implicit tasks may uncover some evidence of increased reliance on abstract word information in the aged.

With respect to explicit memory, our findings indicate that elderly adults are less efficient at recollecting both lexical and perceptual information, even though perceptual information can be a useful retrieval cue (as was demonstrated by the young adults of our study). In contrast to the marked age-related declines observed in the recognition memory test of Experiment 3, we found largely intact priming in Experiment 1, indicating that, in our study, implicit and explicit measures could be dissociated on the basis of age. Format changes also provided evidence of a dissociation between implicit and explicit measures with respect to young adults (older adults' performance was uniformly inferior to that of young adults across all the study conditions and item types). That is, input modality affected both priming and recognition memory, whereas voice only influenced priming.

In sum, the results of this study replicate earlier findings of intact abstract and modality-specific priming in old age and provide an explanation for the contradictory findings reported in the memory literature with respect to the processing of fine-grained perceptual information in old age. Additional studies exploring the factors that may govern the availability of fine-grained perceptual information in implicit tests are needed to clarify the specific sources of the age-related declines uncovered here and in some earlier studies.

\section{REFERENCES}

Balota, D. A., \& Ferraro, R. (1993). A dissociation of frequency and regularity effects in pronunciation performance across young adults, older adults, and individuals with senile dementia of the Alzheimer type. Journal of Memory \& Language, 32, 573-592.

Balota, D. A., \& Ferraro, R. (1996). Lexical, sublexical, and implicit memory processes in healthy young adults and healthy older adults and in individuals with dementia of the Alzheimer type. Neuropsychology, 10, 82-95.

Chiarello, C., \& Hoyer, W. J. (1988). Adult age differences in implicit and explicit memory: Time course and encoding effects. Psychology \& Aging, 3, 358-366.

Church, B. A., \& Schacter, D. L. (1994). Perceptual specificity of auditory priming: Implicit memory for voice intonation and fundamental frequency. Journal of Experimental Psychology: Learning, Memory, \& Cognition, 20, 521-533.

CoHEn, B. H. (2001). Explaining psychological statistics (2nd ed.). New York: Wiley.

Craik, F. I. M., Moscovitch, M., \& McDowd, J. M. (1994). Contributions of surface and conceptual information to performance on implicit and explicit memory tasks. Journal of Experimental Psychology: Learning, Memory, \& Cognition, 20, 864-875.

Davis, H. P., Cohen, A., Gandy, M., Colombo, P., VandusselDORP, G., Simolke, N., \& Romano, J. (1990). Lexical priming deficits as a function of age. Behavioral Neuroscience, 104, 288-297.

Fleischman, D. A., \& Gabrieli, J. D. E. (1998). Repetition priming in normal aging and Alzheimer's disease: A review of findings and theories. Psychology \& Aging, 13, 88-119.

Florentine, M., Reed, C. M., Rabinowitz, W. M., Braida, L. D., Durlach, N. I., \& BuUs, S. (1993). Intensity perception: XIV. Intensity discrimination in listeners with sensorineural hearing loss. Journal of the Acoustical Society of America, 94, 2575-2586.

Gibson, J. M., Brooks, J. O., Friedman, L., \& Yesavage, J. A. (1993). Typography manipulations can affect priming of word stem completion in older and younger adults. Psychology \& Aging, 8, 481-489.

Goldinger, S. D. (1996). Words and voices: Episodic traces in spoken word identification and recognition memory. Journal of Experimental Psychology: Learning, Memory, \& Cognition, 22, 1166-1183.

Goldinger, S. D. (1998). Echoes of echoes? An episodic theory of lexical access. Psychological Review, 105, 251-279.

HintzMAN, D. L. (1986). "Schema abstraction" in a multiple-trace memory model. Psychological Review, 93, 411-428.

Hintzman, D. L., Block, R. A., \& Inskeep, N. R. (1972). Memory for mode of input. Journal of Verbal Learning \& Verbal Behavior, 11, 741-749.

Howard, D. V., Fry, A. F., \& Brune, C. M. (1991). Aging and memory for new associations: Direct versus indirect measures. Journal of Experimental Psychology: Learning, Memory, \& Cognition, 17, 779-792.

Hultsch, D. F., Masson, M. E. J., \& Small, B. J. (1991). Adult age differences in direct and indirect tests of memory. Journals of Gerontology, 46, $\mathrm{P} 22-\mathrm{P} 30$.

JACKSON, A., \& MORTON, J. (1984). Facilitation of auditory word recognition. Memory \& Cognition, 12, 568-574.

JACOBY, L. L., \& HAYMAN, C. A. G. (1987). Specific visual transfer in word identification: Remembering without awareness. Journal of Experimental Psychology: Learning, Memory, \& Cognition, 13, 456463.

JAVA, R. I., \& Gardiner, J. M. (1991). Priming and aging: Further evidence of preserved memory function. American Journal of Psychology, 104, 89-100.

Karayanidis, F., Andrews, S., Ward, P. B., \& McConaghy, N. (1993). Event-related potentials and repetition priming in young, middle-aged and elderly normal subjects. Cognitive Brain Research, 1, 123-134.

Kausler, D. H., \& PucKett, J. M. (1980). Adult age differences in recognition memory for a nonsemantic attribute. Experimental Aging Research, 6, 349-355.

Kausler, D. H. \& Puckett, J. M. (1981a). Adult age differences in memory for modality attributes. Experimental Aging Research, 7, 117-125.

Kausler, D. H., \& Puckett, J. M. (1981b). Adult age differences in memory for sex of voice. Journal of Gerontology, 36, 44-50.

KIRSNER, K. (1974). Modality differences in recognition memory for words and their attributes. Journal of Experimental Psychology, 102, 579-584.

Kirsner, K., Dunn, J. C., \& Standen, P. (1989). Domain-specific resources in word recognition. In S. Lewandowsky, J. C. Dunn, \& 
K. Kirsner (Eds.), Implicit memory: Theoretical issues (pp. 99-122) Hillsdale, NJ: Erlbaum.

KonIG, E. (1957). Pitch discrimination and age. Acta Otolaryngologica, 48, 475-489.

KuČERA, M., \& Francis, W. N. (1967). Computationalanalysis of presentday American English. Providence, RI: Brown University Press.

Light, L. L., La Voie, D., Valencia-Laver, D., Albertson Owens, S. A., \& MEAD, G. (1992). Direct and indirect measures of memory for modality in young and older adults. Journal of Experimental Psychology: Learning, Memory, \& Cognition, 18, 1284-1297.

Light, L. L., \& Singh, A (1987). Implicit and explicit memory in young and older adults. Journal of Experimental Psychology: Learning, Memory, \& Cognition, 13, 531-541.

MACKAY, D. G. (1992). Constraints on theories of inner speech. In D. Reisberg (Ed.), Auditory imagery (pp. 121-149) Hillsdale, NJ: Erlbaum.

Mrtchell, D. B. (1989). How many memory systems? Evidence from aging. Journal of Experimental Psychology: Learning, Memory, \& Cognition, 15, 31-49.

Mitchell, D. B., Hunt, R. R. \& Schmitt, F. A. (1986). The generation effect and reality monitoring: Evidence from dementia and normal aging. Journal of Gerontology, 41, 79-84.

Moore, B. C. J., Peters, R. W., \& Glasberg, B. R. (1992). Detection of temporal gaps in sinusoids by elderly subjects with or without hearing loss. Journal of the Acoustical Society of America, 92, 1923 1932.

Moscovitch, M. (1982). Multiple dissociations of function in amnesia. In L. S. Cermak (Ed.), Human memory and amnesia (pp. 337-370). Hillsdale, NJ: Erlbaum.

Nusbaum, H. C., Pisoni, D. B., \& Davis, C. K. (1984). Sizing up the Hoosier mental lexicon: Measuring the familiarity of 20,000 words. Research in speech perception (Progress Rep. No. 10). Bloomington: Indiana University Press.

Olsho, L. W., Harkins, S. W., \& Lenhardt, M. L. (1985). Aging and the auditory system. In J. E. Birren \& K. W. Schaie (Eds.), Handbook of the psychology of aging (2nd ed., pp. 332-377). New York: Van Nostrand Reinhold.

Palmeri, T. J., Goldinger, S. D., \& Pisoni, D. B. (1993). Episodic encoding of voice attributes and recognition memory for spoken words. Journal of Experimental Psychology: Learning, Memory, \& Cognition, 19, 309-328.

PARK, D. C., \& Puglisi, J. T. (1985). Older adults' memory for the color of pictures and words. Journal of Gerontology, 40, 198-204.

Pilotti, M., Bergman, E. T., Gallo, D. A., Sommers, M., \& RoediGER, H. L., III (2000). Direct comparison of auditory implicit memory tests. Psychonomic Bulletin \& Review, 7, 347-353.

RAJARAm, S., \& RoEdiger, H. L., III (1993). Direct comparison of four implicit memory tests. Journal of Experimental Psychology: Learning, Memory, \& Cognition, 19, 765-776.

Roediger, H. L., III, \& McDermott, K. B. (1993). Implicit memory in normal human subjects. In F. Boller \& J. Grafman (Eds.), Handbook of neuropsychology (Vol. 8, pp. 63-131). Amsterdam: Elsevier.

Roediger, H. L., III, Weldon, M. S., \& Challis, B. H. (1989). Explaining dissociations between implicit and explicit measures of retention: A processing account. In H. L. Roediger III \& F. I. M. Craik
(Eds.), Varieties of memory and consciousness: Essays in honour of Endel Tulving (pp. 3-42). Hillsdale, NJ: Erlbaum.

Schacter, D. L., \& Church, B. A. (1992). Auditory priming: Implicit and explicit memory for words and voices. Journal of Experimental Psychology: Learning, Memory, \& Cognition, 18, 915-930.

Schacter, D. L., Church, B. A., \& Osowiecki, D. M. (1994). Auditory priming in elderly adults: Impairment of voice-specific implicit memory. Memory, 2, 295-323.

SchNeIDER, B. (1997). Psychoacoustics and aging: Implication for everyday listening. Journal of Speech-Language Pathology and Audiology, 21, 111-124.

SHIPLEY, W. C. (1940). A self-administering scale for measuring intellectual impairment and deterioration. Journal of Psychology, 9, 371377.

Snodgrass, J. G., \& Feenan, K. (1990). Priming effects in picture fragment completion: Support for the perceptual closure hypothesis. Journal of Experimental Psychology: General, 119, 276-296.

Sommers, M. S. (1999). Perceptual specificity and implicit auditory priming in older and younger adults. Journal of Experimental Psychology: Learning, Memory, \& Cognition, 25, 1236-1255.

SPIELER, D. H., \& BALOTA, D. A. (2000). Factors influencing word naming in younger and older adults. Psychology \& Aging, 15, 225-231.

Stine, E. L., Wingfield, A., \& Poon, L. W. (1986). How much and how fast: Rapid processing of spoken language in later adulthood. Psychology \& Aging, 1, 303-311.

VAn Orden, G. C., \& Goldinger, S. D. (1994). The interdependence of form and function in cognitive systems explains perception of printed words. Journal of Experimental Psychology: Human Perception \& Performance, 20, 1269-1291.

Wingfield, A., Poon, L. W., Lombardi, L., \& Lowe, D. (1985). Speed of processing in normal aging: Effects of speech rate, linguistic structure, and processing time. Journal of Gerontology, 40, 579-585.

\section{NOTE}

1. In both Experiments 1 and 2, prior to the analyses of the priming scores, identification rates for studied and nonstudied items following each study condition were examined to ascertain whether the level of priming was above baseline. The level of significance for a priori comparisons was determined via the Sequentially Rejective Multiple Test procedure(Cohen, 2001). In these analyses, there was only one case in which the priming scores displayed in Tables 1-3 did not reflect a reliable priming effect. Specifically, in the E-D condition, young adults failed to identify DM items at a reliably higher rate than nonstudied items $(t=1.20$, n.s. $)$, whereas older adults yielded reliable priming effects for these items $[t(15)=5.30]$. However, when the E-D and the D-D conditions were combined, these items yielded reliable priming effects in both young and older adults $(t \mathrm{~s}>3.20)$. This finding suggests that Experiment 1 yielded age-equivalent abstract priming.

(Manuscript received November 29, 1999; revision accepted for publication November 30, 2001.) 